\title{
The Role Of Intelligence, Surveillance, And Reconnaissance In Disaster And Public Health Emergency
}

\author{
Unal Demirtas, MD; Yusuf Ziya Turk, MD; Mustafa Ozer, MD
}

Gulhane Military Medical Academy Military Health Services, Ankara, Turkey

Correspondence:

Unal Demirtas, MD

Gulhane Military Medical Academy

Military Health Services

General Doktor Tevfik Sağlam Cad.

Ankara Keçiören 06010, Turkey

\begin{abstract}
Abbreviations:
ADF: Australian Defence Force

ISR: Intelligence, Surveillance, and

Reconnaissance

OSINT: open source intelligence

USAID: US Agency for International

Development
\end{abstract}

Received: February 27, 2014

Accepted: April 17, 2014

Online publication: September 16, 2014

doi:10.1017/S1049023X14001009
In the last few years, intelligence, surveillance, and reconnaissance (ISR) capabilities have played an important role in humanitarian assistance and disaster relief. ISR assets help identify for first responders, federal civil agencies, and government and private aid organizations, the areas where relief efforts should be focused and what kind of supplies and aid victims need. ${ }^{1}$

Intelligence, surveillance, and reconnaissance is a rubric used by the joint forces to describe all activities associated with collecting, integrating, analyzing, disseminating and exploiting militarily relevant information about other nations and non-state actors. It includes not only the secret information collected by technical means and human agents, but also open-source intelligence gleaned from places like the Internet. Practitioners often distinguish between strategic ISR that is of interest to national agencies or multiple military services, and more perishable tactical intelligence that is only of use to particular fighting units in specific circumstances, but there is no clear dividing line between the two areas. Whatever the nature of the information, a complete ISR system necessarily includes collection systems for acquiring raw data, hardware and software for fusing the data into a meaningful picture, analytic tools for interpreting that picture, and networks for moving the processed information to potential users in a timely fashion. ${ }^{2}$

In this context, NATO defined the terms involved in ISR:

1. Intelligence: the product resulting from the processing of information concerning foreign nations, hostile or potentially hostile forces or elements, or areas of actual or potential operations

2. Surveillance: the systematic observation of aerospace, surface or subsurface areas, places, persons, or things, by visual, aural, electronic, photographic, or other means

3. Reconnaissance: a mission undertaken to obtain, by visual observation or other detection methods, information about the activities and resources of an enemy or potential enemy, or to secure data concerning the meteorological, hydrographic, or geographic characteristics of a particular area

4. ISR: the capability that integrates command direction, sensors, and processed formation and intelligence with timely dissemination in order to provide decision makers with effective "Situational Awareness."

The Role of ISR in Disaster Response

Intelligence activities are very important for postdisaster search and rescue teams sent to the region to effectively, precisely and quickly begin operations. Following a natural disaster, there is a concurrent increase in social and health needs, and deterioration in the infrastructure and the systems needed to respond to those needs. Governmental and relief organizations are faced with the task of prioritizing and delivering services to the affected population.

The purpose of emergency management is to collect subjective and objective information in order to measure damage and identify those basic needs of the affected population that require immediate response. The process comprises describing the extent of the emergency, the measurement of its current and potential future impact, assessing the existing response and immediate additional needs, and recommending priority action.

Decision-making will be aided by the availability of relevant health information. However, immediately after an event, the information may not be readily available, and 
for data that are available or sought, compromise may be needed with respect to its completeness and comprehensiveness, in conjunction with the timeliness of its availability.

Community surveying and surveillance of communities form part of the process of needs identification. The health information collected should be shared with other agencies in order to aid the effective coordination of the disaster response.

World Health Organization protocols indicate the multiple sources of information that should be used to help clarify a situation; with the use of four main forms of data:

1. Review of existing information

2. Visual inspection of the affected area

3. Interviews with key informants

4. Rapid surveys.

In response to a natural disaster, the setting up of a surveillance system is a recognized component of the information gathering system, and its purpose is to guide actions of public health importance. ${ }^{4}$

Said to have been coined in the mid-1990s by the then Vice Chairman of the United States Joint Chiefs of Staff, Admiral William Owens, ISR has come to be seen as a vital component of the revolution in military affairs and a defining concept of information age warfare. ${ }^{5,6}$

For the Australian Defence Force (ADF), the most important aspect of the change in operations heralded by the information age is "the ability to increase vastly the speed and capacity to collect, organize, store, process, tailor and distribute information.", 7

This ability is encapsulated in ISR, which has been growing in prominence in the ADF in recent years, and is defined as "... an activity that synchronises and integrates the planning and operation of sensors, assets, and processing, exploitation, and dissemination systems in direct support of current and future operations. This is an integrated intelligence and operations function. ${ }^{6,8}$

\section{References}

1. Petitjean MM. Intelligence Support to Disaster Relief and Humanitarian Assistance. Intelligencer: Journal of U.S. Intelligence Studies. 2013;19(3):57-60.

2. Barber J. An Intelligence, Surveillance And Reconnaissance (ISR) Vision For The Canadian Forces. Canadian Military Journal. Winter 2001-2002:41-46.

3. AAP-06 NATO Glossary of Terms and Definitions (English and French). Edition 2013.

4. Disaster Intelligence-Methods for the Wellington Region for use after a Natural Disaster: An Appendix to the Regional Public Health Emergency Management Plan. http://www.ttophs.govt.nz/vdb/document/311 Accessed February 2, 2014.

5. Deptula DA, Brown RG. A house divided: the indivisibility of intelligence, surveillance, and reconnaissance. Air E Space Power Journal. 2008;xxii(2):6.

6. Hallen T. Airborne Intelligence, Surveillance and Reconaissance for the Future Australian Defence Force Flight. www.raaf.gov.au/airpower. Accessed November 12, 2013.
ISR support should therefore be focused on providing the information necessary to address the gaps in commanders' situational awareness in order to allow decision superiority to be achieved. ${ }^{9}$

\section{An Example of The Use of ISR Assets}

One of the best examples of the use of ISR assets in humanitarian operations occurred on January 12, 2010, when a 7.0 magnitude earthquake struck Haiti, killing 230,000 and leaving widespread destruction in the capital of Port au Prince and rural areas. The US Agency for International Development (USAID) took the lead for disaster relief, and on January 13th the US military received orders to assist relief efforts. ${ }^{10}$ USAID and military personnel needed to know how much and what kind of damage the earthquake caused. US government planners relied on two primary intelligence disciplines: open source intelligence (OSINT) and imagery intelligence to assess the damage. OSINT sources included news reports and information posted on social media networks describing the damage. ${ }^{11}$

This information provided insights into the local situation and needs of the people living in the country. Imagery was collected by Navy P-3 "Orion" aircraft and the new RQ-4 "Global Hawk" unmanned aerial vehicle as well as imagery satellites. ${ }^{11}$ These platforms provided full motion video and still imagery that was key to understanding the status of roads, bridges, air and sea ports, and Haitian government buildings. ${ }^{12}$

This information helped planners determine how to get relief workers and supplies into Haiti and how to transport those people and supplies once they were in country. ${ }^{1}$

ISR has proven its worth in humanitarian assistance and disaster relief operations several times over the last decade. All of the intelligence disciplines contributed to damage assessments, the protection of relief workers and the delivery of supplies to where they were needed most. Most importantly, these efforts helped ease human suffering. Because of this, and despite the challenges that remain, ISR's role in these operations will likely increase in the future. ${ }^{1}$

7. Department of Defence. Defence 2000: Our Future Defence Force. Defence Publishing Service, Canberra, 2000:108.

8. Department of Defence. Australian Defence Glossary. http://adg.eas.defence. mil.adgms/. Accessed August 12, 2013.

9. Joint Doctrine Publication 3-52 (JDP 3-52) (2nd Edition). June 2008. https:// www.gov.uk/government/uploads/system/uploads/attachment_data/file/43340/jdp3522 nded.pdf. Accessed February 3, 2014.

10. Ryan J, Goerhing R, Hulslander R. USSOUTHCOM and Joint Task Force-Haiti...some challenges and considerations in forming a joint task force. Joint Center for Operational Analysis Journal. 2010;XII(2):1.

11. Buddelmeyer K. Lessons Learned From Hurricane Katrina. Masters thesis, Air Command and Staff College, 2007.

12. Fraser D, Hertzelle W. Haiti relief: an international effort enabled through air, space and cyberspace. Air \& Space Power Journal. 2010;XXIV(4):9. 